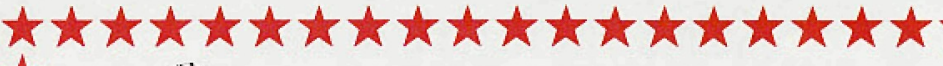

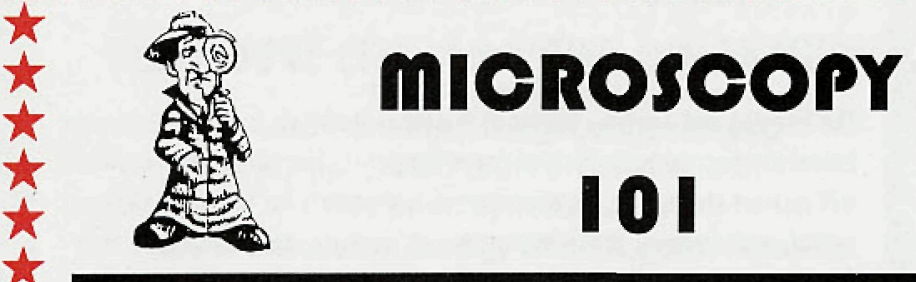

We appreciate the response to this publication feature - and weicome all contributions. Contributions may be sent to Phil Oshel, our Technical Editor at:

$\begin{array}{ll}\text { Mr. Phil Oshel } & \text { (608)833-2885 } \\ \text { PO Box 620068 } & \text { Fax: (608)836-1969 } \\ \text { Middleton WI 53562 } & \text { eMail: oshel@terracom.net }\end{array}$

\section{Hydrofluoric Acid Safety}

Hydrofluoric Acid is a very dangerous reagent. It is only a weak acid but it acts like a toxin. So, you can get dangerous amounts on yourself and not know it. The dangers are maiming, amputation, and death. A single drop, if not treated, has caused fingers to be amputated, and a 25 square inch spill can cause death, if not treated properly.

Microfabrication facilities (both academic and industry) use lots of $H F$, but there are few problems, because they understand what they are doing and have invested in protective gear and the necessary medical supplies. The problems occur in labs who use HF only once or once in awhile. This is where the horror stories typically come from, and I think making mica samples fails into this category.

My advice is: If you are already used to using HF and have all the needed facilities, go ahead with the mica work. It's nothing that you have not done before. If you don't have experience or the equipment for $\mathrm{HF}$ work, find a lab on campus who does (a microfabrication facility, for example) and do it there. If there isn't a lab with experience, either don't do the experiment or spend the time and money to do it right. Nobody should die for their research (and with $\mathrm{HF}$, this has happened).

The sci.chem newsgroup has periodic discussions on HF. From those discussions I have a few references that anyone using or planning to use HF should have:

1) Symptoms and treatment of HF injuries. D. Peters and $R$. Miethchen Journal of Fluorine Chemistry vol.79, pp 161-165 (1996).

2) Recommended medical treatment of $H F$ acid exposure. Allied Signal HF Products Division. Morristown NJ (800) 622-5002.

Ken Westra, MicroFab, University of Alberta

\section{Making Silianted Slides For Mounting Sections}

We have found it very useful over the years. I can not take credit, however, the method originally came from G. Farmillo, a technical specialist at Dimension Laboratories, Canada (unpublished).

Silanated Slides

(Aptex: 3-aminopropyltriethoxysilane from Sigma)

1. Wash slides in detergent.

2. Rinse in running tapwater $10-15$ minutes.

3. Rinse in distilled water.

4. Rinse in acetone 5 minutes.

5. Coat in $2 \%(\mathrm{~V} / \mathrm{v})$ Aptex in acetone 5 minutes.

6. Rinse in luke-warm running tap water 2 minutes.

7. Rinse in distilled water.
8. Air or oven dry at $40^{\circ} \mathrm{C}$ in a dust-free area.

9. Wrap, and store at room temperature up to 1 month, or at $-20^{\circ} \mathrm{C}$ for several months. Freshly coated slides are best.

\section{Dr. Sharon Miksys, University of Toronto}

\section{Increasing the Intensity of DAB Chromagen in BrdU Immunohistochemistry}

I do a lot of BrdU staining and image analysis. While consulting on a cell proliferation study (not here at UNC), there was a processing problem (with the dehydrants) which resulted in decreased, faint and in some cases no visible chromagen (DAB). Also, we had a project here that involved decalcification and we did not get the intensity of staining that I prefer for image analysis. Both of these problems were resolved by the following method which may be helpful (or may not, all things being unequal). I should note that we use the Dako anti-BrdU and the Dako Envision Kit. This is my basic or start off procedure for most of my antibndies without steps 1 to 6 and step 10 is here just a different antibody. The hydrolyzation step and the pepsin step are usually not needed.

BrdU Immunohistochemistry (using the Dako Envision kit)

1) Hydrate slides to double distilled $\mathrm{H} 20$ as per standard procedures.

2) Hydrolyze with $4 \mathrm{~N} \mathrm{HCL}$ at $37^{\circ} \mathrm{C}$ for 20 minutes.

3) Rinse with double distilled $\mathrm{H}_{2} \mathrm{O}$ once for 1 minute at room temperature.

4) Transfer slides to double distilled $\mathrm{H}_{2} \mathrm{O}$ (kept at $37^{\circ} \mathrm{C}$ ) for 5 minutes.

5) Incubate in pepsin solution (Dako) at $37^{\circ} \mathrm{C}$ for 15 minutes. All of the remaining steps are performed at room temperature.

6) Rinse twice with double distilled $\mathrm{H}_{2} \mathrm{O}, 1$ minute each rinse.

7) Rinse twice with phosphate buffered saline containing $1 \%$ Tween 20 (PBSt), 3 minutes each rinse.

8) Place in Blocking Reagent $\left(\mathrm{H}_{2} \mathrm{O}_{2}\right)$ for 5 minutes.

9) Repeat step 7

10) Place in primary antibody (anti-BrdU) and incubate for 10 minutes; use a 1:200 dilution (20 minute incubation time for preputial gland only).

11) Repeat step 7

12) Place in polymer labeled secondary antibody and incubate for 10 minutes.

13) Rinse well with double distilled $\mathrm{H}_{2} \mathrm{O}$.

14) Incubate with working DAB solution (1 drop DAB per $1 \mathrm{ml}$ buffer) for $8 \mathrm{~min}$ utes.

15) Rinse well with double distilled $\mathrm{H}_{2} \mathrm{O}$.

16) Place in DAB Enhancer solution (Innovex) and incubate for 5 minutes.

17) Rinse well with double distilled $\mathrm{H}_{2} \mathrm{O}$.

18) Stain with Aqua Hematoxylin (Innovex) for 35 seconds and rinse with tap water.

19) Place in tap water for 5 minutes.

Dehydrate and coverslip (we use Permount, Fisher) according to standard procedures. The difference between this procedure and our normal one is the pepsin.

Robert Schoonhoven, University of North Carolinal Linda Meeker, Dow Corning, Midland, MI

\section{Phosphotungstic Acid, Water, and Histologic Stains}

If you're preparing Mallory's trichrome stain from scratch, be aware that the phosphotungstic acid (PTA) concentration may be critical. Unless you take pains to ensure reproducibility, you may encounter unpredictable staining results. PTA functions as a dye excluder, so that the operative acid dyes can stain differentially. If not enough PTA is present, the acid dyes will perform as though no PTA is present and NOT stain differentially.

PTA is hygroscopic. It naturally absorbs moisture from the atmosphere. In 